\title{
PROJETO DE MELHORIA DE SAÚDE BUCAL REALIZADO EM REGIÃO AMAZÔNICA (MONTE NEGRO, RO)
}

\author{
*Prof. Dr. José Roberto de Magalhães Bastos, **Prof. Dr. Luis Marcelo Aranha Camargo, \\ ***Profa. Ms. Roberta Franscisca Martins de Castro, ****Prof. Dr. Ricardo Henrique Alves da Silva
}

\section{RESUMO}

O projeto de melhoria de saúde bucal é um trabalho da Universidade de São Paulo (USP) iniciado em 2002, através da análise e planejamento das atividades, passando a contar, a partir de 2003, com atendimento odontológico feito por acadêmicos e pós-graduandos, sob supervisão docente, da Faculdade de Odontologia de Bauru e sob os auspícios do Núcleo Avançado de Pesquisa da USP em Rondônia. Este trabalho objetivou realizar uma análise descritiva da atuação em tal projeto nas diversas viagens realizadas desde o mês de julho de 2003 , abordando atividades de cunho educativo, preventivo e curativo. Os números demonstram uma necessidade de uma maior abrangência do serviço de saúde a populações econômica e socialmente desfavorecidas, bem como a importância de projetos de extensão universitária em tais localidades.

Palavras-chave: Saúde pública. Saúde bucal. Odontologia.

\section{ABSTRACT}

The Improvement of Oral Health Project of the University of São Paulo (USP) was initiated in 2002, first by the analysis and planning of the activities, then by including, in 2003, dental care given by the Dentistry undergraduate and graduate students, under teaching supervision, from the Bauru Dental School in co-operation with de Advanced Research Unit of USP in Rondonia. This work aimed to carry through a descriptive analysis of the performance in all trips taken by the ones involved in this project since July 2003, where educative, preventive and curative activities were performed. The numbers demonstrate a necessity of a greater reach of health services to economical and socially unfavourable population, as well as the importance of university extension projects in these places.

Key words: Public health. Oral health. Dentistry.

\footnotetext{
* Professor Titular da Faculdade de Odontologia de Bauru da USP (FOB-USP) - e-mail: zeromaba@fob.usp.br ** Coordenador do Instituto de Ciências Biomédicas 5 da USP (ICB-5-USP) - e-mail: spider@icb5usp.med.br *** Mestre em Odontologia em Saúde Coletiva pela Faculdade de Odontologia de Bauru da USP (FOB-USP) e professora das Faculdades São Lucas (Porto Velho-RO) - e-mail: roberta@icb5usp.med.br **** Professor da Faculdade de Odontologia de Ribeirão Preto da USP (FORPUSP) - e-mail: ricardohenrique@usp.br
} 


\section{INTRODUÇÃO}

Em populações social e economicamente desfavorecidas, a prevalência de doenças passíveis de prevenção geralmente se apresenta mais elevada quando em comparação com localidades mais desenvolvidas. A cárie dentária e a doença periodontal também seguem esse padrão de distribuição, seja por falta de informação da população sobre os cuidados com a higiene bucal, seja por falta de acesso ao tratamento odontológico propriamente dito.

O estado de Rondônia tem sido polo de pesquisa em doenças tropicais e conta com um Núcleo Avançado de Pesquisa da Universidade de São Paulo (USP). O Núcleo denominado Instituto de Giências Biomédicas 5 (ICB-5) fica localizado no município de Monte Negro, situado a $250 \mathrm{~km}$ da capital, Porto Velho (figura I).

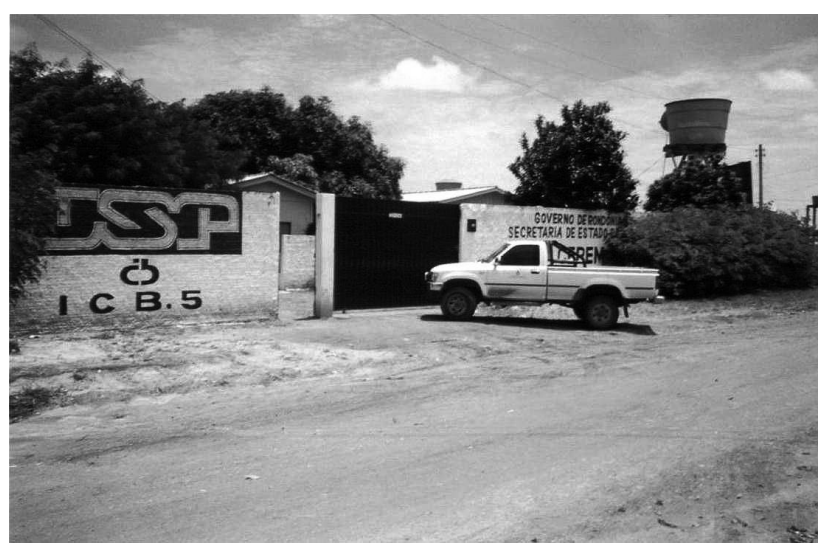

Figura I - Fachada do Instituto de Giências Biomédicas 5, Monte Negro, Rondônia

Tem população jovem, na maioria imigrantes do sul e sudeste e perfil nosológico marcado por doenças infectoparasitárias, muito embora com incremento recente na prevalência de doenças crônicodegenerativas (CAMARGO, 2002). De acordo com o Censo Demográfico realizado em 2000 pelo Instituto Brasileiro de Geografia e Estatística (IBGE), Monte Negro conta com 12.627 habitantes, sendo que mais da metade vive em área rural com densidade demográfica de $8,9 \mathrm{hab} / \mathrm{km}^{2}$.

A carência de atenção em saúde bucal na região foi despertada pela presença dos médicos/cientistas que trabalham junto ao ICB-5 e, a partir daí, foi realizada uma parceria entre o ICB- 5 e a Faculdade de Odontologia de Bauru (FOB), também pertencente à
USP. A parceria, bem como o apoio financeiro da PróReitoria e do Fundo de Cultura e Extensão da USP, tem viabilizado a ida periódica de uma equipe de docentes e alunos de graduação e pós-graduação da FOB para prestação de serviços em Odontologia e Fonoaudiologia.

Apresenta-se nesse trabalho uma análise da logística desenvolvida pelo Programa, bem como um resumo dos atendimentos e demais atividades desenvolvidas pelas mais variadas equipes presentes na localidade, desde o início do Projeto no ano de 2002. A população também tem sido atendida por alunos de Fonoaudiologia, diretamente supervisionados por docente doutor do Departamento de Fonoaudiologia da FOB-USP.

\section{SITUAÇÃO INICIAL}

O número médio de dentes cariados, perdidos e obturados (índice CPOD) do Estado de Rondônia foi de 4,99 em crianças de 12 anos de idade, o mais alto no levantamento epidemiológico nacional de I996. A média nacional foi de 3,06 para a mesma idade, enquanto a média do Estado de São Paulo foi de 2,28 (BRASIL, I996). O levantamento epidemiológico de I996 abrangeu somente as capitais das unidades de federação, restando, então, a dúvida se esse seria o quadro real do Estado, uma vez que há indícios de que os níveis de cárie sejam mais elevados em municípios de pequeno porte, mais comuns no Estado de Rondônia.

O GPOD médio para a faixa etária de 0 a I4 anos no município de Monte Negro foi de 3,5 em I998, segundo o Sistema Municipal de Informação em Saúde (2003). Não se sabe ao certo a confiabilidade dessa média, assim, o CPOD poderia estar sendo subestimado. De qualquer forma, um CPOD igual a 3,5 denota uma prevalência de cárie considerada moderada pela Organização Mundial de Saúde (OMS). De acordo com a OMS, as crianças de 12 anos de idade deveriam apresentar CPOD igual ou menor a 3, O para o ano de 2000 , sendo que, idealmente, $50 \%$ estariam livres de cárie. Não há dados a respeito dessa idadeíndice para o município de Monte Negro.

A cidade não conta com fluoretação das águas de abastecimento e não há indícios de que a água dos poços usados pela população contenha concentrações significantes de flúor (CAMARGO, 2002), o que possibilitaria redução nos índices de cárie (BASTING et al., I997). 
Baldani, Narvai e Antunes (2002) analisaram as relações entre cárie e fatores socioeconômicos do estado do Paraná, observando que os municípios com melhores condições de vida tendem a apresentar menor agravo da doença.

Seguindo essa mesma tendência, Maltz e Silva (200I) encontraram que os alunos matriculados na rede particular de ensino apresentavam melhor condição de saúde bucal que os alunos da rede pública, demonstrando-se principalmente pelo percentual de crianças livres de cárie aos I2 anos $(47,5 \%$ e $27,5 \%$ nas redes particular e pública, respectivamente).

Em relação ao acesso à água fluoretada, Sampaio (2000) encontrou CPOD 2,5 em crianças de I2 anos de idade que recebiam água fluoretada natural ou artificialmente e 3,9 para aquelas que usavam água com baixa concentração de flúor no Estado da Paraíba. Basting, Pereira e Meneghin (2002) observaram redução de $79 \%$ na prevalência de cárie medida pelo índice GPOD em crianças de 7 a 12 anos de idade no município de Piracicaba, SP, no período entre I97I e I996.

\section{LOGÍSTICA DA EQUIPE DE TRABALHO}

Os alunos de graduação e de pós-graduação participantes das atividades do Projeto de Melhoria de Saúde Bucal de Monte Negro são divididos em frentes de trabalho durante o período de duração do Projeto, realizada da seguinte maneira (figuras 2 e 3 ):

- Procedimentos educativos: Escola Estadual Mato Grosso, Creche São Francisco de Assis, Zona rural e Clínica Prof. Dr. João Adolfo Galdas Navarro.

- Procedimentos preventivos: Escola Estadual Mato Grosso e Clínica Prof. Dr. João Adolfo C. Navarro.

- Procedimentos curativos: Escola Estadual Mato Grosso, Zona rural e Clínica Prof. Dr. João Adolfo Galdas Navarro.

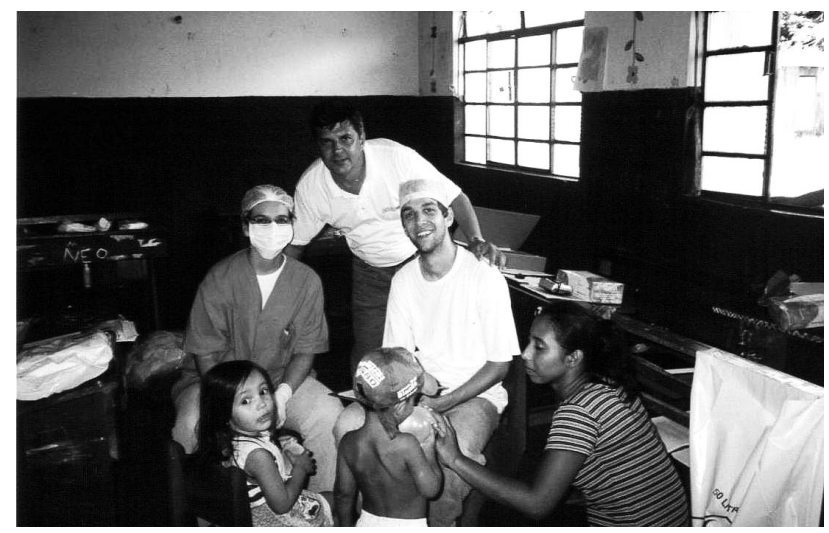

Figura 2 - Atendimento em área rural, Monte Negro, RO

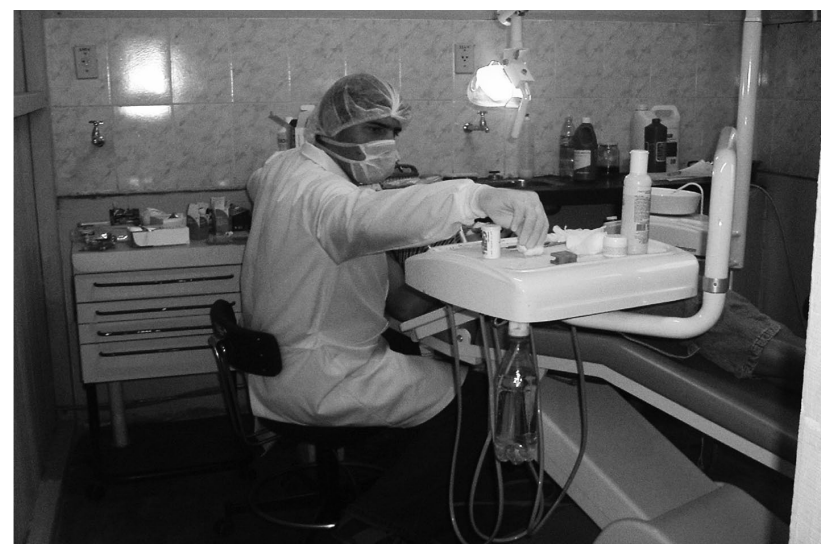

Figura 3 - Atendimento odontológico em área urbana, Centro de Saúde Bucal Prof. Dr. João Adolfo G. Navarro, Monte Negro, RO

O transporte dos alunos e do material necessário para as localidades onde deveria ser realizado o atendimento é feito com a utilização de peruas e camionetas, com motoristas da própria localidade, sob responsabilidade do ICB-5 e em parceria com a Liga Independente de Saúde Rural.

\section{ATUAÇÃO DA EQUIPE ODONTOLÓGICA SEGUNDO OS NÍVEIS DE PREVENÇÃO DA DOENÇA}

O número total de pacientes atendidos pelo projeto, desde o seu início, já tendo sido completadas oito viagens da FOB-USP para o município de Monte Negro, perfazem mais de dez mil procedimentos realizados, em pouco mais de cinco mil pacientes.

Segundo Leavell e Clark (I958), cada doença 
tem sua própria maneira de evoluir se deixada ao seu curso natural. A interferência em qualquer fase desse curso poderia ser então chamada de prevenção, uma vez que impediria que a doença provocasse algum dano mais elevado. Assim, há diferentes níveis de prevenção de uma mesma enfermidade em que o profissional pode atuar.

O primeiro nível de prevenção é o de promoção de saúde, em que se coloca o indivíduo em um ambiente favorável à saúde, criando as condições para que resista ao ataque das doenças em geral. O profissional atua, portanto, de maneira inespecífica, orientando sobre cuidados básicos em saúde (LEAVELL \& GLARK, I958).

Nesse sentido, o Projeto de Melhoria de Saúde Bucal da População de Monte Negro-RO realiza atividades educativas, conscientizando professores da rede pública sobre a necessidade de higiene e manutenção da saúde bucal através de palestras. Além disso, existem ações voltadas à população, realizando sessões de escovação supervisionada com adultos e crianças, na Escola Estadual de Ensino Fundamental Mato Grosso, ao mesmo tempo em que uma equipe de profissionais fica à disposição para eventuais dúvidas do público presente. No período noturno, quando a equipe está presente em Monte Negro, há o agendamento de palestras na Escola Mato Grosso, abordando temas como: saúde bucal; doenças sexualmente transmissíveis; higiene; entre outros.

Para o desenvolvimento das atividades de escovação supervisionada, especificou-se as orientações através da técnica de escovação de Fones para as crianças e as técnicas de Bass e Stillman para os indivíduos adultos (DARBY \& WALSH, 1995). Essa abordagem busca atingir o maior número possível de habitantes do município a fim de se obter uma reprodução do conhecimento e abrangência de promoção de saúde.

O segundo nível de prevenção abrange medidas específicas e reconhecidamente eficazes na proteção contra determinadas doenças, tendo como exemplo a aplicação de vacinas. A atuação ocorre de maneira a prevenir a ocorrência de determinada doença (LEAVELL \& GLARK, I958).

Para a prevenção da cárie dentária, um método comprovadamente eficaz é a fluoretação da água de abastecimento público (FREIRE \& FREIRE, I962; PINTO, 2000; BASTOS, LOPES \& RAMIRES, 200I). Como em Monte Negro essa medida não é oferecida à população, optou-se pela aplicação tópica de flúor em gel a I,23\% $\mathrm{F}^{-}$na clínica odontológica ou em solução para bochecho a $0,2 \% \mathrm{~F}^{-}$na Escola Mato Grosso em todas as pessoas entre 6 e I 5 anos de idade que passaram por atendimento odontológico.

O terceiro nível de prevenção refere-se a diagnóstico e tratamento precoce das doenças que não foram evitadas seja por não se conhecer métodos para atuação em nível anterior ou porque os métodos existentes não foram aplicados. Procura-se deter a evolução da doença através de providências adequadas no sentido de identificá-las e tratá-las o mais cedo possível (LEAVELL \& GLARK, I958). Gitando Chaves (I986) "no câncer oral, por exemplo, o diagnóstico precoce e o tratamento imediato constituem a melhor forma à nossa disposição no momento para enfrentar o problema”.

Em Monte Negro, sempre que há suspeita, biópsias são realizadas a fim de buscar esclarecimentos de lesões suspeitas, com posterior encaminhamento para análise histopatológica em laboratório da região.

Frente às falhas na aplicação das medidas de primeiro ao terceiro nível, procura-se evitar um mal maior, isto é, busca-se a limitação do dano causado pela doença, o que caracteriza o quarto nível de prevenção. Em decorrência das condições encontradas, no quarto nível encontra-se a maior atuação da equipe de saúde bucal no município.

Um dos métodos utilizados é o tratamento restaurador atraumático, conhecido pela sigla ART, possibilitando ao paciente máxima preservação do dente, mantendo todas as suas funções originais, sejam estéticas ou mastigatórias. A técnica consiste no isolamento do dente com roletes de algodão para a remoção de esmalte desmineralizado sem suporte dentinário e do tecido cariado não recuperável através do uso de curetas e outros instrumentos manuais. Quando necessária, é realizada a proteção da polpa com material de pH básico, a base de hidróxido de cálcio. Após a remoção da cárie, realiza-se o condicionamento da cavidade com um agente ácido, que em seguida é removido com água. A cavidade é então seca com algodão ou papel absorvente e o material restaurador, conhecido como cimento de ionômero de vidro, inserido na cavidade dentária, sendo necessária sua proteção imediata com um verniz ou com vaselina para evitar que ocorra embebição devido ao meio úmido da boca enquanto não há a presa completa (endurecimento) do cimento (FRENCKEN, I996). 
A principal vantagem proporcionada pelo uso do cimento de ionômero de vidro é a sua propriedade de liberar flúor no meio bucal, além de uma resistência satisfatória. Sua principal limitação é o custo, ainda bastante elevado no mercado nacional.

Utilizou-se também uma adaptação dessa técnica, sendo que os procedimentos foram executados na mesma sequência, exceto pelo condicionamento ácido, mas o material restaurador foi substituído por IRM (material restaurador intermediário). O uso desse material oferece redução de quarenta vezes no custo e também proporciona resultados satisfatórios para utilização em programas de saúde coletiva, embora, por ser um material mais solúvel, apresente redução da eficiência mastigatória, além de não apresentar coloração compatível com a dentição natural, não podendo ser usado como material estético, sendo, por estes motivos, considerado como um material restaurador de caráter provisório (OLIVEIRA, 2000).

Além destas técnicas, há também os métodos convencionais, utilizando-se o material conhecido como amálgama de prata para dentes posteriores e resina composta para dentes anteriores. As cavidades eram preparadas com canetas de alta e baixa rotação com brocas para remoção de cárie.

Quando a cárie se encontrava em estágio avançado e o paciente apresentava sintomatologia característica de inflamação pulpar irreversível, optava-se pela extração do elemento dentário (exodontia) devido a ausência de aparelhos de raios-X, essencial para a correta execução de procedimentos de tratamento e obturação do canal pulpar, bem como a ausência e impossibilidade (principalmente temporal) na realização de tratamentos endodônticos.

O paciente sempre era esclarecido da possibilidade de se manter o dente em função caso fosse feito o tratamento de canal e sempre que manifestava opção por buscar o tratamento em outras localidades o dente recebia um curativo de demora. Outras causas de extração foram doença periodontal avançada, com perda de tecido de suporte e mobilidade dentária, dentes decíduos impedindo a erupção de dentes permanentes, fraturas de coroas dentárias por trauma e, principalmente, destruição severa do dente por cárie. A extração dentária ainda é um dos procedimentos mais presentes na atuação da equipe.

O quinto e último nível de prevenção refere-se a reabilitação do paciente, quando a doença já evoluiu a ponto de atingir a sua fase final (LEAVELL \& CLARK, I958). Em Odontologia, essa atuação seria caracterizada pela perda do elemento dentário por doença periodontal, cárie ou trauma, necessitando de reabilitação através da instalação de próteses dentárias, cuja atuação ainda é restrita, mas paulatinamente esforços vêm sendo realizados através de projetos de pesquisa e parcerias para a sua viabilização em maior número.

Além disso, o Projeto foi agraciado pelo CNPq com um fomento a fim de instalar essa experiência de sucesso em Monte Negro na população ribeirinha dos Rios Machado e Preto, no município de Porto Velho, entre os anos 2005 e 2006 (SILVA, 2008). E, ainda referente a parceria FOB e ICB-5, o Projeto de Melhoria de Saúde Bucal vem sendo ampliado para outras localidades do estado, tais como os municípios de Machadinho d'Oeste (e o distrito de Tabajara), Santa Luzia d'Oeste e Nova Brasilândia d'Oeste.

\section{CONSIDERAÇÕES FINAIS}

A concretização do projeto permite enfatizar a importância dos programas de extensão universitária, haja vista ser esta uma das funções da universidade pública. Os alunos podem tomar contato com outras realidades em âmbito social, econômico e cultural, podendo perceber as grandes diferenças existentes em nosso país. A atuação extramuros, além de proporcionar amplo aprendizado aos participantes, oferece a possibilidade de atenção odontológica gratuita, melhorando assim o quadro de saúde bucal e a qualidade de vida da população.

\section{REFERÊNCIAS BIBLIOGRÁFICAS}

BALDANI, M. H.; NARVAI, P. C.; ANTUNES, J. L. F., 2002. Cárie dentária e condições socioeconômicas no Estado do Paraná, Brasil. Cad. Saúde Pública.v. I8, p. 755-763, 1996.

BASTING, R. T.; PEREIRA, A. G.; MENEGHiM, M. G. Avaliação da prevalência de cárie dentária em escolares do município de Piracicaba, SP, Brasil, após 25 anos de fluoretação das águas de abastecimento público. Rev. Odontol. Univ. São Paulo, v. II, p. 287-292, 1997.

BASTOS, J. R. M.; LOPES, E. S.; RAMIRES, I. Manual de 
Odontologia Preventiva \& Social. Bauru: Faculdade de Odontologia de Bauru, 284 p., 2001.

BRASIL. MINISTÉRIO DA SAÚDE. Levantamento epidemiológico em saúde bucal, I996, cárie dental. Brasília: Área técnica de saúde bucal, MS-BR, I996.

CAMARGO, L. M. A. et al. A rural community in a Brazilian Western Amazonian Region: some demographic and epidemiological patterns. Memórias Inst. Oswaldo Cruz, v. 97, p. I93-I95, 2002.

CHAVES, M. M. Odontologia Social. São Paulo: Editora Artes Médicas, I986.

DARBY, M. L.; WALSH, M. M. Dental hygiene theory and practice. Philadelphia: Editora W. B. Saunders, I995.

FREIRE, P. S.; FREIRE, A. S. Resultados de 7 anos de fluoretação de águas no Brasil. Rev. Bras. Odontol., v. 2I, p. 3I-4I, I962.

FRENCKEN, J. E. et al. Atraumatic restorative treatment (ART): rationale, technique, and development. J. Publ. Health Dent., v. 56, p. I35-I40, I996.

INSTITUTO BRASILEIRO DE GEOGRAFIA E ESTATÍSTICA. Disponível em http://www.ibge.gov.br/cidades. Acesso em nov. 2005.

LEAVELL, H. R.; GLARK, E. G. Preventive medicine for the doctor in his community: an epidemiologic approach. 2. ed. New York: McGraw-Hill. 689 p. 1958.

MALTZ, M.; SILVA, B. B. Relação entre cárie, gengivite e fluorose e nível socioeconômico em escolares. Rev. Saúde Pública, v. 35, p. I70-I76, 2001.

OLIVEIRA, L. M. G. Avaliaçäo de um programa de tratamento restaurador atraumático em crianças institucionalizadas. Tese de doutorado, Rio de Janeiro: Faculdade de Odontologia, Universidade Federal do Rio de Janeiro, 2000.

PINTO, V. G. Saúde Bucal Coletiva. São Paulo: Editora Santos, 2000.

RONDÔNIA. SISTEMA MUNICIPAL DE INFORMAÇÃO EM SAÚDE. Disponível em: http://www.rondonia.ro.gov.br/prefeituras/indicadores/montenegro. htm. Acesso em nov. 2003.

SAMPAIO, F. C. Dental caries and sugar intake of children from rural areas with different water fluoride levels in Paraiba, Brazil. Commun. Dent. Oral. Epidem., v. 28, p. 307-313, 2000.

SILVA, R. H. A. et al. Cárie dentária em população ribeirinha do Estado de Rondônia, Região Amazônica, Brasil, 2005/2006. Cad. Saúde Pública, v. 24, n. IO, p. 2347-53, 2008 . 